\title{
Cytocompatibility and Viscoelastic Properties of Phthalate Ester-free Tissue Conditioners
}

\author{
Yoshiya HASHIMOTO and Masaaki NAKAMURA \\ Department of Biomaterials, Osaka Dental University, 8-1, Kuzuhahanazono-cho, Hirakata 573-1121, Osaka, Japan \\ Corresponding author, E-mail:yoshiya@cc.osaka-dent.ac.jp
}

Received June 15, 2004/Accepted July 22, 2004

\begin{abstract}
We prepared prototype phthalate ester-free tissue conditioners (PFT) from a powder of poly (ethyl methacrylate) and a mixture of several liquids, including di-n-butyl sebacate, benzyl benzoate (BB), and ethanol. The estrogenic activities of the liquids in the PFT were measured by an E-screen assay. We also assessed the cytotoxicity of the prototype and commercial tissue conditioners against a living skin equivalent. Finally, the viscoelastic properties were determined by measuring the rubber hardness and initial flow, while the effect of the mixing liquid on the mechanical properties of a denture resin was assessed by three-point bending test. PFT did not show any estrogenic activity and displayed a low or a similar level of cytotoxicity as the conventional materials. The viscoelastic properties and the effect of the mixing liquid on mechanical properties were influenced by the quantity of BB present in the mixing liquid. The prototype is therefore a reasonable PFT candidate.
\end{abstract}

Key words: Cytocompatibility, Phthalate ester-free, Tissue conditioners

\section{INTRODUCTION}

The disruption of animal reproductive systems in the wild has been attributed to environmental contaminants that mimic the effects of estradiol ${ }^{1)}$. In fact, a number of chemical contaminants have estrogenic activity when tested in biological systems ${ }^{2)}$. In addition, a few chemicals used as dental materials may be estrogenic xenobiotics ${ }^{3-5)}$.

To better understand the cytocompatibility of biomaterials, one key approach is to deter the interaction between cells and materials in vitro ${ }^{6-8)}$. An in vitro study showed that a small number of phthalates were weakly estrogenic in a recombinant yeast screen and an E-screen ${ }^{9)}$. In an in vivo study, Ema et $a .^{10)}$ reported that cleft palate, fusion of the sternebrae, and dilatation of the renal pelvis occurred in pregnant rats which were given butyl benzyl phthalate by gastric intubation. Our previous study $^{11)}$ also showed that when phthalate esters were used as plasticizers, four commercial tissue conditioners containing these plasticizers exhibited estrogenic activity in vitro. Therefore, to avoid potential problems due to estrogenic activity, it is necessary to develop new phthalate ester-free tissue conditioners (PFT).

One phthalate-free plasticizer candidate is di-nbutyl sebacate (DBS), which we have found is not estrogenic $^{12)}$. In addition, prototype tissue conditioners made from DBS show less cytotoxicity than those from phthalate esters ${ }^{12)}$. Benzyl benzoate (BB) is another phthalate ester-free plasticizer candidate that lacks estrogenic activity ${ }^{11)}$. This plasticizer has been widely used as a main- or sub-plasticizer in commercial tissue conditioners ${ }^{11,13)}$.

Few studies are available on the physical and chemical properties or the biocompatibility of PFT. Therefore, in the current study, we investigated the cytocompatibility and viscoelasticity of PFT as well as the effect of DBS and $\mathrm{BB}$ on the mechanical properties of a denture resin.

\section{MATERIALS AND METHODS}

\section{Materials and specimens preparation}

Table 1 lists the sources used to make PFT - namely $\mathrm{DBS}, \mathrm{BB}$, and ethanol (EtOH), as well as BPA (Bisphenol-A) which was used as a positive control. Experimental PFT specimens were made of poly (ethyl methacrylate) powder (Shofu Inc., Kyoyo, Japan) mixed with various concentrations of DBS, $\mathrm{BB}$, and ethanol (Table 2). All materials were of reagent grade and were used without further purification. Three commercial tissue conditioners were listed in Table 3 .

\section{$M C F-7$ cells and $E$-screen test}

We first examined whether the experimental liquids mimicked the activity of estradiol in an E-screen assay. This assay has been widely applied to identify estrogenic chemicals and determine their relative potencies. The assay uses breast tumor-derived MCF7 cells to compare the ability of chemicals to mimic growth stimulation by estradiol. The reported detection limit of $10 \mathrm{pg} / \mathrm{ml} 17 \beta$-estradiol makes the Escreen one of the most sensitive assays for assessing estrogenicity ${ }^{14)}$.

MCF-7 cells were provided by Dr. Sonnenschein 
(Tufts University). The cells were plated in 24-well plates at initial concentration of $4 \times 10^{4} \mathrm{cells} / \mathrm{ml} /$ well in Dulbecco's modified Eagle's medium (DMEM; Nissui, Tokyo, Japan) containing 5\% fetal bovine serum (FBS; Hyclone, Utah, USA). After 24 hours, the medium was replaced with phenol red-free DMEM (GIBCO, NY, USA) containing 5\% FBS (which had been treated to remove endogenous steroids) and different concentrations of test chemicals $\left(10^{-8}-10^{-3} \mathrm{~g} / \mathrm{mL}\right)$. After 144 hours, the medium was removed to determine cell proliferation. Negative control consisted of cell culture medium containing 0.1\% DMSO (dimethyl sulfoxide, Nacalai Tesque, Kyoto, Japan).

Four samples of each test chemical were prepared. Cell proliferation in the E-screen assay was assessed using the SRB assay, in which SRB binds to the basic amino acids of cellular macromolecules. Absorbance was measured using a microplate reader equipped with a $540 \mathrm{~nm}$ filter. Values reported represent the average-fold increase over control from triplicate measurements. Differences between the different test chemical groups were performed by oneway ANOVA followed by a Tukey test.

\section{Living Skin Equivalent (LSE) and analysis of cytotoxicity by WST assay}

The cytotoxicity of the three prototype and commercially available tissue conditioners was tested in a LSE system. LSE is an organotypic co-culture of human dermal fibroblasts in a collagen-containing matrix, and therefore has two viable and metaboli- cally active cell populations - fibroblasts and keratinocytes ${ }^{15)}$. In this way, LSE possesses biosynthetic properties that approximate their in vivo counterparts. In normal oral mucosa, these cells usually exist in the oral epithelium and lamina propia. For these reasons, LSE is a suitable system for evaluating the cytotoxicity of tissue conditioners.

The three prototype PFT specimens were mixed at a polymer/experimental liquid $(\mathrm{P} / \mathrm{L})$ ratio of 1.2 by weight, and the three commercial tissue conditioners were prepared according to manufacturers' instructions (Table 3). Four samples were prepared for each material type. The samples were prepared in stainless steel molds $(10-\mathrm{mm}$ diameter $\times 2-\mathrm{mm}$ height), clamped between stainless steel plates, and stored for 5 minutes at $37^{\circ} \mathrm{C}$. TESTSKIN, an artificial human LSE system (TOYOBO, Osaka, Japan), was exposed to these samples for 6 or 24 hours.

Cytotoxicity in TESTSKIN was assessed using the WST assay, which is based on the cleavage of the tetrazolium salt WST-1 by mitochondrogenase found in viable cells. A volume of $100 \mu \mathrm{L}$ of Cell Count Reagent SF (Nacalai Tesque, Kyoto, Japan) was added to each well. After incubation for 1 hour at $37^{\circ} \mathrm{C}$, the absorbance of each well was measured at $450 \mathrm{~nm}$ with a reference wavelength at $655 \mathrm{~nm}$. The values reported represent the average percentage of control from triplicate measurements. To determine the independent and combined effects of the exposure time on these samples, comparisons between groups were performed by two-way ANOVA followed by a Tukey test.

Table 1 Chemicals used in this study

\begin{tabular}{llll}
\hline \multicolumn{1}{c}{ Chemical } & Code & \multicolumn{1}{c}{ Manufacturer } & \multicolumn{1}{c}{ Batch } \\
\hline Di-n-butyl sebacate & DBS & Daihachi Chem, Osaka, Japan & N-2020 \\
Benzyl benzoate & BB & Nacalai Tesque, Kyoto, Japan & MOT3521 \\
Ethyl alcohol & EtOH & Wako Chem, Osaka, Japan & KGQ2903 \\
Bisphenol-A & BPA & Tokyo Kasei, Tokyo, Japan & GG01-DK \\
\hline
\end{tabular}

Table 2 Composition of the experimental liquids

\begin{tabular}{lcccc}
\hline & \multirow{2}{*}{ Code } & \multicolumn{3}{c}{ Liquid (wt\%) } \\
\cline { 3 - 5 } & & DBS & BB & EtOH \\
\hline Experimental A & ExA & 85 & 0 & 15 \\
Experimental B & ExB & 70 & 15 & 15 \\
Experimental C & ExC & 50 & 35 & 15 \\
\hline
\end{tabular}

Table 3 Commercial tissue conditioners tested in this study

\begin{tabular}{lcll}
\hline \multicolumn{1}{c}{ Material } & Code & \multicolumn{1}{c}{ Manufacturer } & \multicolumn{1}{c}{ Batch Number } \\
\hline Shofu Tissue Conditioner & TC & Shofu Inc., Kyoyo, Japan & P: 100134/L: 100113 \\
Coe Comfort & CC & GC America Inc., IL, USA & P: 062100B/L: 091900A \\
Fictioner & FT & Nissin, Japan & P: BFA/L: BGE \\
\hline
\end{tabular}




\section{Rubber hardness of prototype and commercial tissue} conditioners

The hardness of the biomaterials was determined using a Shore A durometer (KOBUNSHI SEIKI, Kyoto, Japan). A three-piece stainless steel mold was constructed to make and cure the standardized cylindrical test specimens. Dimensions of the specimens generated with this mold were $25 \mathrm{~mm}$ (diameter) $\times 10 \mathrm{~mm}$ (thickness). After each sample was stored in water at $37^{\circ} \mathrm{C}$ for 1 and 24 hours and 3,7 , 14,21 , and 30 days, three hardness measurements were made at different positions on the specimen. Each hardness value represents the mean of the three measurements. To determine the independent and combined effects of the exposure time on these samples, comparisons between groups were performed by two-way ANOVA followed by a Tukey test.

Initial flow study of prototype and commercial tissue conditioners

Initial flow was determined using a parallel-plate plastimeter. Three samples were prepared for each material type. A 1-ml volume of freshly mixed tissue conditioner was placed on glass plate after 2,3 , 4 , and 5 minutes. Next, a constant load of $0.98 \mathrm{~N}$ was applied for 30 seconds at $37^{\circ} \mathrm{C}$ using another glass plate. The flow of material was evaluated by measuring the diameter of the disc produced between the parallel plates. Each initial flow value represents the mean of three measurements. To determine the independent and combined effects of the exposure time on these samples, comparisons between groups were performed by two-way ANOVA followed by a Tukey test.

Effects of experimental liquids on the mechanical properties of a denture resin

Three blocks of heat-polymerizing resin (Shofu Inc., Kyoto, Japan) were produced in $2.0 \times 2.0 \times 25 \mathrm{~mm}$ metal mold. The heat-polymerizing resin was mixed in a ratio of $10.0 \mathrm{~g}$ powder to $4.5 \mathrm{~mL}$ monomer and was polymerized in a metal mold under pressure of 100 to $300 \mathrm{kgf} / \mathrm{cm}^{2}$ at $100^{\circ} \mathrm{C}$ for 10 minutes. After polymerization, the polymerized specimen was annealed at $100^{\circ} \mathrm{C}$ for 8 hours. The specimens were stored at $37^{\circ} \mathrm{C}$ for 1 and 7 days in experimental liquids. A three-point bending test was performed in air at $21^{\circ} \mathrm{C}$ by applying a vertical load at the midpoint of each specimen at a cross-head speed of 5 $\mathrm{mm} / \mathrm{min}$ using a load-testing machine (Instron 5567, Massachusetts, USA). The complete force versus deflection history of each test was plotted on a chart recorder. Flexural modulus and maximum stress at fracture were then obtained from the plots.

Flexural modulus $\mathrm{E}$, in $\mathrm{MPa}$, was calculated from the following equation:

$$
\mathrm{E}=\mathrm{F}_{1} \mathrm{l}^{3} / 4 \mathrm{bh}^{3} \mathrm{~d}
$$

where

$\mathrm{F}_{1}$ is the load, in $\mathrm{N}$, at a convenient point in the strain-line portion of the trace;

$\mathrm{l}$ is the distance, in $\mathrm{mm}$;

$\mathrm{b}$ is the width, in $\mathrm{mm}$;

$\mathrm{h}$ is the height, in $\mathrm{mm}$; and

$\mathrm{d}$ is the deflection, in $\mathrm{mm}$, at load $\mathrm{F}_{1}$.

Each set of flexural modulus and maximum stress at fracture values represents the mean of three measurements. To determine the independent and combined effects of the exposure time on these samples, comparisons between groups were performed by two-way ANOVA followed by a Tukey test to analyze the data.

\section{RESULTS}

\section{Estrogenic activity}

As shown in Fig. 1, although the positive control, bisphenol-A, stimulated MCF-7 cell growth, the three experimental liquids did not significantly enhance the growth compared to the negative control.

\section{Cytotoxicity}

Fig. 2 shows the cytotoxicity of the tissue conditioners in the LSE system as assessed by WST assay. Cell viability was not affected by the 6 -hour treat-

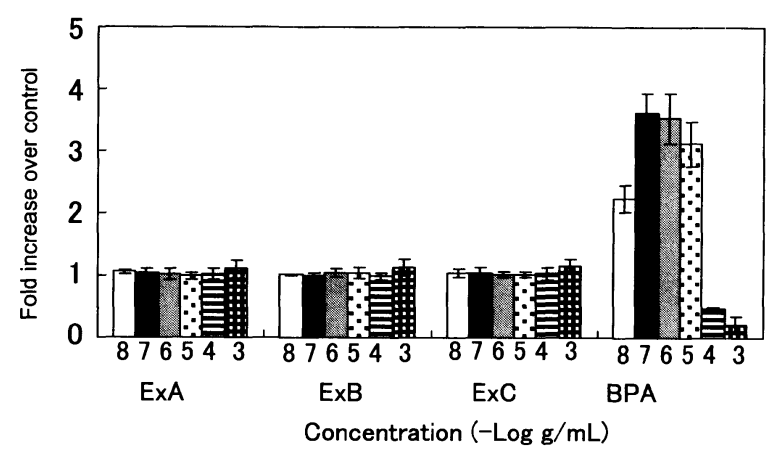

Fig. 1 Estrogenic activities of the liquids in PFT as assessed by the E-screen test using SRB assay.

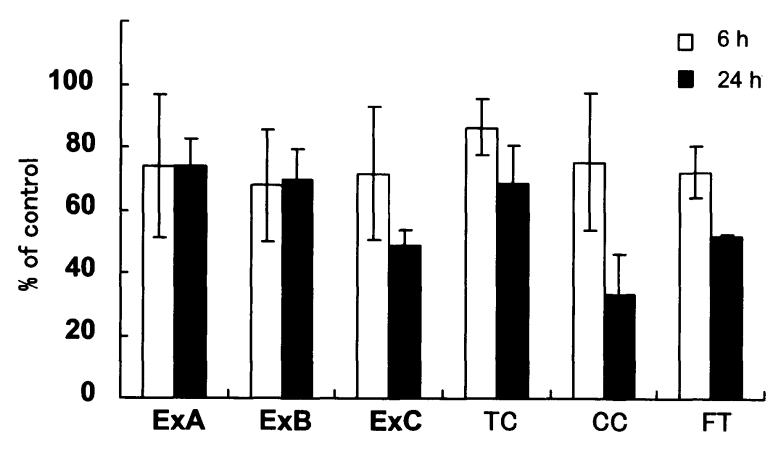

Fig. 2 Cytotoxicity of PFT and three commercial tissue conditioners using the WST assay. 


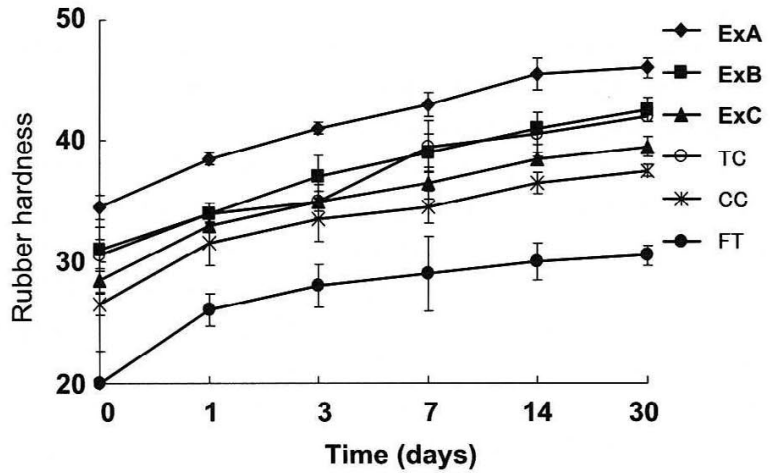

Fig. 3 Rubber hardness of prototype and commercial tissue conditioners using a Shore A durometer.

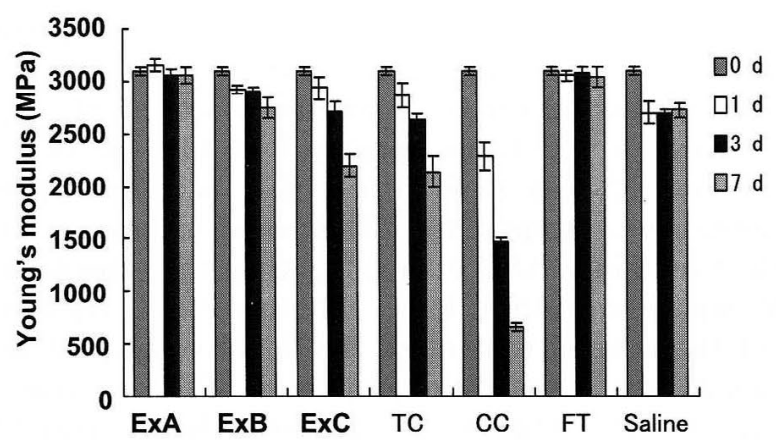

(a)

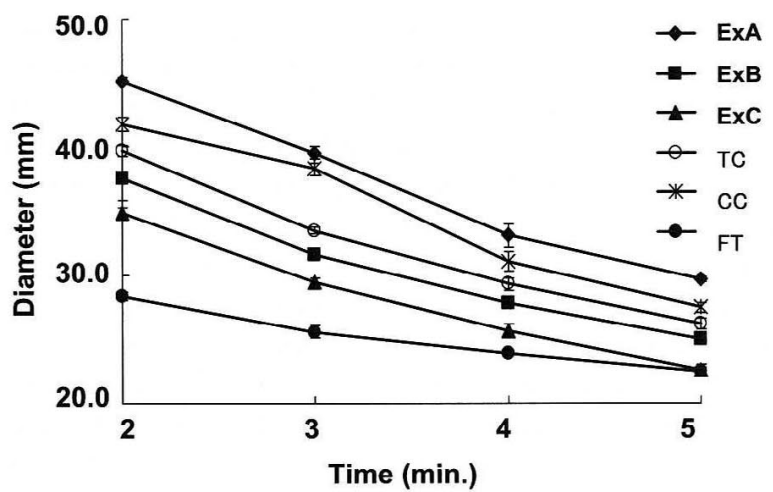

Fig. 4 Initial flow of prototype and commercial tissue conditioners using a parallel-plate plastimeter.

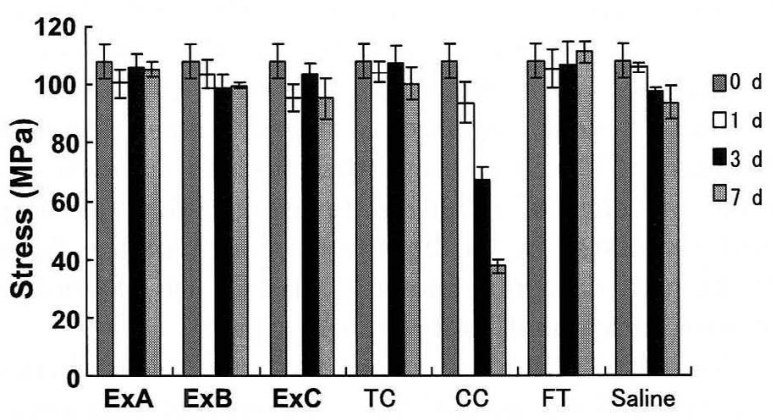

(b)

Fig. 5 (a) Effects of experimental liquids on the fracture modulus of denture resin.

(b) Effects of experimental liquids on the maximum stress of denture resin.

ment with any of the tissue conditioners. However, all of the tissue conditioners reduced cell viability after 24 hours $(\mathrm{p}<0.05)$. At this time point, CC reduced cell viability most substantially $(\mathrm{p}<0.05)$. Cell viability following a 24-hour treatment with $\mathrm{ExC}$ and FT was also reduced $(p<0.05)$, although it was less substantial compared to that by $\mathrm{CC}$.

\section{Mechanical properties}

1) Rubber hardness

Fig. 3 shows the rubber hardness of the prototype and commercial tissue conditioners. The rubber hardness of all tissue conditioners tested increased progressively with time. At all time points, ExA and FT showed the highest and lowest rubber hardness respectively. The rubber hardness values of $\mathrm{ExB}$ and $\mathrm{TC}$ were the second highest after 14 and 30 days.

2 ) Initial flow

Fig. 4 shows the initial flow of prototype and commercial tissue conditioners. In this assay, a higher diameter represents a higher flow. The flow of all tissue conditioners decreased progressively with time. Until the $4^{\text {th }}$ minute time point, the order of the initial flow was ExA $>$ CC $>$ TC $>$ ExB $>$ ExC $>$ FT.
Effects of experimental liquids on the mechanical properties of a denture resin

\section{1) Young's modulus}

Fig. 5(a) shows the Young's modulus of a denture resin. The Young's modulus of the denture resin decreased progressively with time when stored in ExC, $\mathrm{TC}$, and $\mathrm{CC}$ liquids.

\section{2) Maximum stress}

Fig. 5(b) shows the maximum stress of the denture resin. Only the $\mathrm{CC}$ liquid caused a progressive decrease in the maximum stress of the denture resin with time.

\section{DISCUSSION}

In the current study, we investigated DBS and $\mathrm{BB}$ as new plasticizers for use in PFT. DBS is a plasticizer found in polyvinylidene-chloride films used for packing food, while BB is used not only as a plasticizer for tissue conditioners but also as a cosmetic ingredient ${ }^{16)}$. In this study, we examined the PFT in terms of biocompatibility, viscoelasticity, and their effects on the mechanical properties of a denture material.

The estrogenic activity of the experimental liquids in PFT was assessed by an E-screen assay. Previous studies ${ }^{17)}$ with this assay showed that phthalate 
ester, a commonly used plasticizer, has weak estrogenic activity; however, phthalate ester-free plasticizers, DBS and BB, did not exhibit any estrogenic activity. In the present study, the three experimental liquids containing DBS, BB, and ethanol did not show any estrogenic activity. These results corresponded well with our previous study ${ }^{12}$

We further evaluated the cytotoxicity of the prototype and commercial tissue conditioners in the LSE system. None of the tissue conditioners showed cytotoxicity following 6-hour incubation. However, all of the tissue conditioners showed cytotoxicity after 24 hours. This could be due to the plasticizer present in the tissue conditioners. Prolonged working time might induce cytotoxicity. Our previous study $^{17)}$ showed that the order of cytotoxicity was $\mathrm{BB}>$ phthalate ester plasticizers $>\mathrm{DBS}$, and that increasing $\mathrm{BB}$ content in prototype tissue conditioners corresponded with decreased cell viability. CC, the plasticizer most commonly used, was strongly cytotoxic. FT was also cytotoxic, which could be due to the presence of a phthalate ester (butyl phthalyl butyl glycolate) in the liquid component of the tissue conditioner (data not shown) and the use of another polymer component, butyl methacrylate.

Although phthalate esters that are released from commercial tissue conditioners are weakly estrogenic, it is rather unlikely that any adult intake of phthalate esters will reach the dose necessary to cause adverse effects. Furthermore, embryos and infants are known to be highly sensitive to endocrine disrupt$\mathrm{ers}^{3)}$, but such materials are most likely not used by this age group. On the other hand, given the cytotoxicity of phthalate esters, their release from tissue conditioners should be considered a potential reason for oral diseases of unknown etiology ${ }^{18)}$. In the present study, we showed that prototype tissue conditioners using DBS as a main plasticizer have weak cytotoxicity. Indeed, this plasticizer is not expected to cause any acute oral toxicity or irritate the skin.

Tissue conditioners and soft lining materials have been used as the modern removable prothodontics ${ }^{19)}$ because of their ability to heal inflamed and distorted mucosa ${ }^{20)}$. In the present study, we examined the viscoelastic property of the tissue conditioner as a dynamic impression material. Murata et $a{ }^{21)}$ reported that a dynamic impression material should initially exhibit characteristics similar to those of a tissue conditioning material. In other words, it should flow readily after the denture containing the material is placed in the mouth. However, when the denture is removed and during subsequent cast construction, it should not flow but rather resist permanent deformation. The tissue conditioners changed to a gel over time as the powder and liquid mixed, and also due to the release of $\mathrm{EtOH}^{21)}$. As a result, their viscoelastic properties progressively decreased.

We attempted to control the viscoelastic properties of the PFT by incorporating $\mathrm{BB}$ - which has a strong affinity for polymers. DBS, in contrast, has a low affinity for polymers. Since incorporating only plasticizers in the liquid portion of the PFT might lead to longer gelation time, ethanol is usually incorporated in the liquid component of PEMAcontaining tissue conditioners. Therefore, to control gelation time, we included $15 \%$ ethanol in the experimental liquid for each prototype PFT.

To assess the viscoelastic properties of the prototype PFT and commercial tissue conditioners, we examined them by flow measurement. We found that the degree of $\mathrm{BB}$ incorporation produced significant differences in the initial flow. This is because a low molecular weight and the presence of an aromatic ring give $\mathrm{BB}$ a strong affinity for polymers. On the other hand, although majority portion of the plasticizer in $\mathrm{CC}$ liquid composed of $\mathrm{BB}$, the initial flow for $\mathrm{CC}$ was higher than that of other tissue conditioners, except ExA. This could be because CC liquid contained $8.2 \%$ ethanol $^{22)}$, while the experimental liquids contained 15\%. Murata et al. reported that the ethanol content of the liquid component influenced the viscoelastic properties of tissue conditioners. Accordingly, a higher ethanol content resulted in a higher initial flow. Since the liquid in FT was ethanol-free, until the 4 minute time point, its initial flow was lower than any of the other tissue conditioners. The reasons for the above observations are unclear, but it might be due to the use of butyl methacrylate polymer or differences in the $\mathrm{P} / \mathrm{L}$ ratio.

Next, we examined the rubber hardness of the tissue conditioners, which is an indication of their resilience. The rubber hardness of prototype PFT decreased as the degree of $\mathrm{BB}$ incorporation increased, i.e., the materials became softer. This is probably due to the same reasons that accounted for BB's initial flow - specifically its molecular weight and chemical structure. Although CC liquid contained $87.3 \% \mathrm{BB}^{22)}$, it fared lower in rubber hardness when compared to other tissue conditioners. It was FT which contained butyl methacrylate polymer as the powder - which had the lowest rubber hardness at all time points. Similarly, Parker et al. ${ }^{23)}$ demonstrated that gels based on a $80 / 20$ ratio of butyl methacrylate/ethyl methacrylate copolymer were initially much softer than those based on poly(ethyl methacrylate).

Previous studies reported ${ }^{12)}$ that the flexural strength of heat-polymerizing resin decreased considerably when stored with plasticizers such as BB and benzyl salicylate, which have small molecular weight and a high affinity for PEMA. This could be because these plasticizers penetrated easily into the polymer chain of the denture resin. Indeed, we 
found that the storage of heat-polymerizing resin in $\mathrm{CC}$ and ExC liquids caused a progressive decrease in Young's modulus with time. This was also found when the heat-polymerizing resin was stored in the TC liquid. In the case of TC liquid, the progressive decrease in Young's modulus could be due to the plasticizer, dibutyl phthalate. On the other hand, although the maximum stress of the resin stored in $\mathrm{CC}$ liquid decreased with time, those stored in ExC and TC did not. It is possible that the plasticizer causes fracture of the heat-polymerizing resin before it reaches the yield point; however, heat-polymerizing usually allows sufficient permeation of the liquid component so that it might hold up the yield point due to flexibility. Therefore, these findings indicated that it is absolutely necessary to evaluate the maximum stress and Young's modulus in order to determine the influence of the liquid component of tissue conditioners on heat-polymerizing resin. Although the present study investigated the mechanical strength of heat-polymerizing resin for a period of only seven days, decreases in the fracture strength of heat-polymerizing resin are reported only after 90 days of water storage ${ }^{24)}$. Thus, long-term storage tests should be carried out to obtain a better understanding of the effects of tissue conditioners on denture resin.

In a previous study ${ }^{25)}$, cracking occurred when the resin contacted an organic solvent such as resin monomer, acetone, chloroform, or ethanol. Therefore, penetration of the liquid component from the tissue conditioner into the denture resin is a concern. Yoshida et $a l^{25)}$ reported that conditioning for three days did not affect the bend strength of denture resin. In the current study, we stored the denture resins in the experimental liquids - which was a more severe treatment. Despite the strong affinity of $\mathrm{BB}$ for polymers and the harshness of this treatment, the mechanical properties of denture resin were not affected by storage in $\mathrm{ExB}$ liquid.

In conclusion, the PFT made from combination of $70 \%$ DBS, $15 \% \mathrm{BB}$, and $15 \%$ ethanol was biocompatible, had favorable viscoelasticity, and caused no detrimental effects on denture resin. This prototype is therefore a reasonable PFT candidate. S$R$ Ivoseal $^{\mathrm{TM}}$, the only PFT with DBS, is available in the market. However, the liquid uses considerably more $\mathrm{EtOH}(48.1 \%)^{22)}$. It is believed the $\mathrm{EtOH}$ facilitates the release of plasticizer, since the material exhibits a plastic deformation in the early stage ${ }^{22)}$. Since tissue conditioners are susceptible to colonization by microorganisms, and since the proliferation of microorganisms is not inhibited by weak cytotoxic materials, such as those in the prototype PFT, it may be necessary to incorporate an antibacterial agent in the PFT. Further investigations must be performed, including in vivo and epidemiological studies, to determine the operability, safety, stability, and other clinical aspects of the PFT.

\section{REFERENCES}

1) Colborn T, vom Saal FS, Soto AM. Developmental effects of endocrine-disrupting chemicals in wildlife and humans. Environ Health Perspect 1993; 101: 378-384.

2) Arnold SF, Robinson MK, Notides AC, Guillette Jr. LJ, McLachlan JA. A yeast estrogen screen for examining the relative exposure of cells to natural and xenoestrogens. Environ Health Perspect 1996; 104: 544548.

3) Olea N, Pulgar R, Perez P, Olea-Serrano F, Rivas A, Novillo-Fertrell A, Pedraza V, Soto AM, Sonnenschein C. Estrogenicity of resin-based composites and sealants used in dentistry. Environ Health Perspect 1996; 104: 298-305.

4) Watanabe M, Hase T, Imai Y. Change in the bisphenol - A content in a polycarbonate orthodontic bracket and its leaching characteristics in water. Dent Mater $J$ 2001; 20: 353-358.

5) Hashimoto $Y$, Nakamura M. Estrogenic activity of dental materials and bisphenol $-\mathrm{A}$ related chemicals in vitro. Dent Mater J 2000; 19: 245-262.

6) Kuroda S, Takeda S, Nakamura M. Effects of six particulate metals on osteoblast-like MG-63 and HOS cells in vitro. Dent Mater J 2003; 22: 507-520.

7) Nagai M, Hayakawa T, Fukatsu A, Yamamoto M, Fukumoto M, Nagahama F, Mishima H, Yoshinari M, Nemoto K, Kato T. In vitro study of collagen coating of titanium implants for initial cell attachment. Dent Mater J 2002; 21: 250-260.

8) Sakai T, Takeda S, Nakamura M. The effects of particulate metals on cell viability of osteoblast-like cells in vitro. Dent Mater J 2002; 21: 133-146.

9) Harris CA, Henttu P, Parker MG, Sumpter JP. The estrogenic activity of phthalate esters in vitro. Environ Health Perspect 1997; 105: 802-811.

10) Ema M, Itami T, Kawasaki H. Teratological assessment of diiodomethyl p-tolyl sulfone in rats. Toxicol Lett 1992; 62: 45-52.

11) Hashimoto $Y$, Kawaguchi M, Miyazaki K, Nakamura M. Estrogenic activity of tissue conditioners in vitro. Dent Mater 2003; 19: 341-346.

12) Hashimoto $Y$, Deguchi M, Nakamura M. Development of new phthalate-free ester tissue conditioners. J Jpn Prothodont Soc 2002; 46: 130.

13) Murata $H$, Iwanaga $H$, Shigeto $N$, Hamada $T$. Initial flow of tissue conditioners - influence of composition and structure on gelation. J Oral Rehabil 1993; 20: 177187.

14) Soto AM, Sonnenschein C, Chung KL, Fernandez MF, Olea N, Serrano FO. The E-SCREEN assay as a tool to identify estrogens: an update on estrogenic environmental pollutants. Environ Health Perspect 1995; 103: 113-122.

15) Nagamune $H$, Maeda $T$, Ohkura $K$, Yamamoto $K$, Nakajima M, Kourai H. Evaluation of the cytotoxic effects of bis-quaternary ammonium antimicrobial reagents on human cells. Toxicol In Vitro 2000; 14: 139- 
147.

16) Castle L, Mercer AJ, Startin JR, Gilbert J. Migration from plasticized films into foods. 3. Migration of phthalate, sebacate, citrate and phosphate esters from films used for retail food packaging. Food Addit Contam 1988; 5: 9-20.

17) Nishijima $M$, Hashimoto $Y$, Nakamura $M$. Cytocompatibility of new phthalate ester-free tissue conditioners in vitro. Dent Mater J 2002; 21: 118-132.

18) Dutree-Meulenberg RO, Kozel MM, van Joost T. Burning mouth syndrome: a possible etiologic role for local contact hypersensitivity. J Am Acad Dermatol 1992; 26: 935-940.

19) Hayakawa I, Keh ES, Morizawa M, Muraoka G, Hirano S. A new polyisoprene-based light-curing denture soft lining material. J Dent 2003; 31: 269-274.

20) Dinckal Yanikoglu N, Denizoglu S. An investigation of the tear energy of five soft lining materials. Dent Mater J 2003; 22: 444-451.
21) Murata H, Hamada T, Taguchi N, Shigeto N, Nikawa $\mathrm{H}$. Viscoelastic properties of tissue conditioners - influence of molecular weight of polymer powders and powder/liquid ratio and the clinical implications. $J$ Oral Rehabil 1998; 25: 621-629.

22) Jones DW, Sutow EJ, Hall GC, Tobin WM, Graham BS. Dental soft polymers: plasticizer composite and leachability. Dent Mater 1988; 4: 1-7.

23) Parker S, Braden M. Formulation of tissue conditioners. Biomaterials 1990; 11: 579-584.

24) Takahashi $Y$, Chai J, Kawaguchi M. Equilibrium strengths of denture polymers subjected to long-term water immersion. Int J Prosthodont 1999; 12: 348-352.

25) Yoshida K, Tamanaha $\mathrm{T}$, Asahara $\mathrm{S}$, Minagi $\mathrm{S}$, Ohkawa S, Nagasawa T, Tsuru H. Effect of various tissue conditioners and relining resins on the bending strength of denture base resins. J Jpn Prothodont Soc 1988; 32: 1311-1316. 